DOE/ID-10567

March 1997

\title{
U.S. Advanced Battery Consortium In-Vehicle Battery Testing Procedure
}
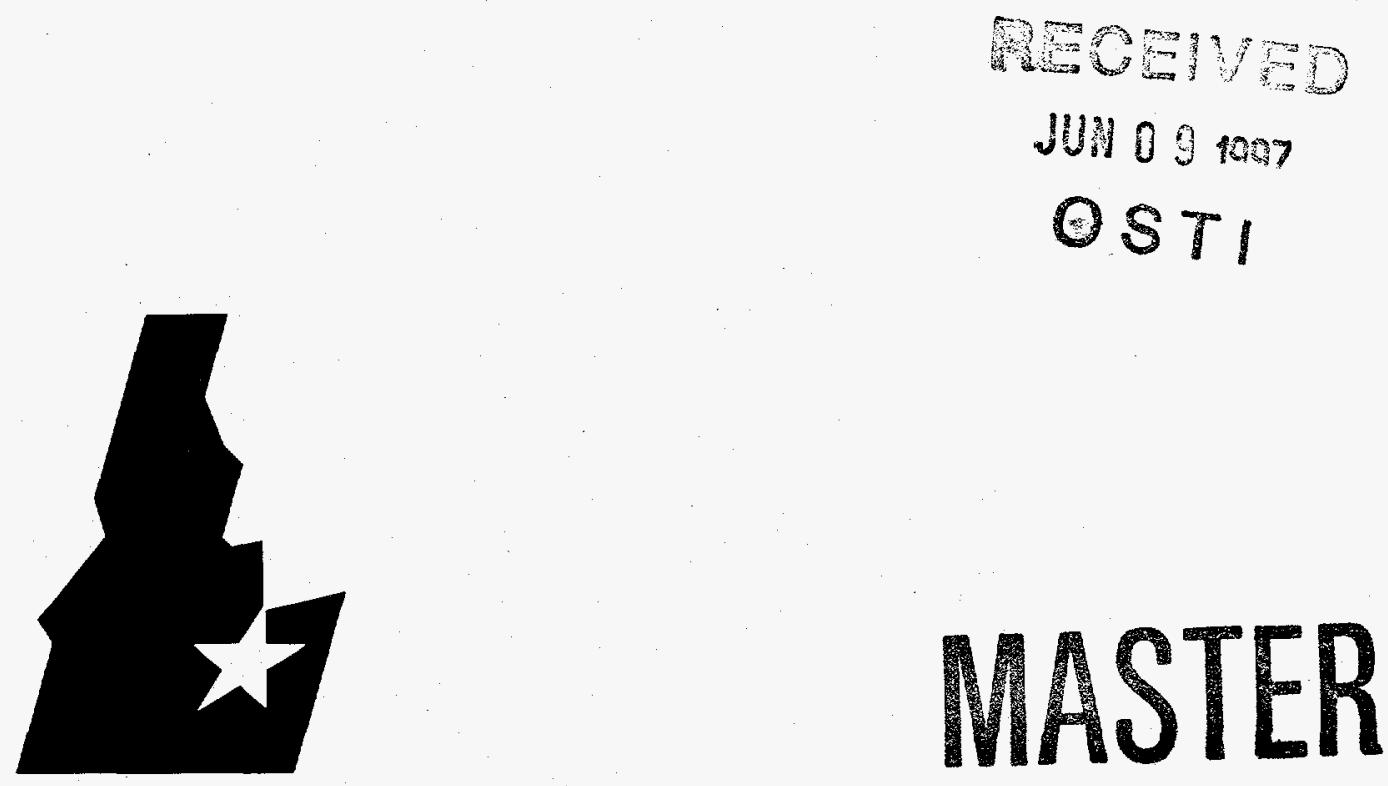

\section{Idaho National Engineering Laboratory}

U.S. Department of Energy $\bullet$ Idaho Operations Office 


\section{DISCLAIMER}

This report was prepared as an account of work sponsored by an agency of the United States Government. Neither the United States Government nor any agency thereof, nor any of their employees, make any warranty, express or implied, or assumes any legal liability or responsibility for the accuracy, completeness, or usefulness of any information, apparatus, product, or process disclosed, or represents that its use would not infringe privately owned rights. Reference herein to any specific commercial product, process, or service by trade name, trademark, manufacturer, or otherwise does not necessarily constitute or imply its endorsement, recommendation, or favoring by the United States Government or any agency thereof. The views and opinions of authors expressed herein do not necessarily state or reflect those of the United States Government or any agency thereof. 


\section{DISCLAMMER}

Portions of this document may be illegible in electronic image products. Images are produced from the best available original document. 


\section{U. S. Advanced Battery Consortium In-Vehicle Battery Testing Procedure}

March 1997

DISTRIBUTION OF THIS DOCUMENT IS UNLIMITED

\section{Prepared for the}

U.S. Department of Energy

Assistant Secretary for Energy Efficiency and Renewable Energy (EE)

Under DOE Idaho Operations Office

Contract DE-AC07-94ID13223 


\section{CONTENTS}

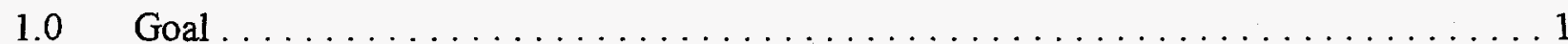

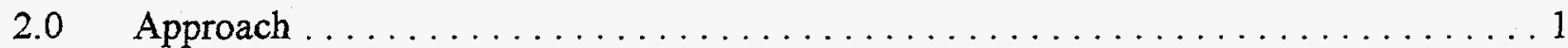

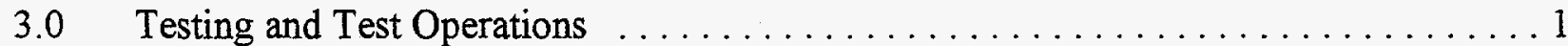

$3.1 \quad$ Battery Acceptance and Installation $\ldots \ldots \ldots \ldots \ldots \ldots \ldots \ldots \ldots$

3.2 Post-Installation Checkout $\ldots \ldots \ldots \ldots \ldots \ldots \ldots \ldots \ldots \ldots \ldots \ldots \ldots \ldots \ldots \ldots \ldots \ldots$

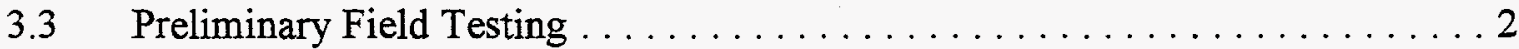

- $\quad$ vehicle compatibility checks

- $\quad$ preliminary vehicle/battery performance trials

- battery charging

- $\quad$ break-in testing

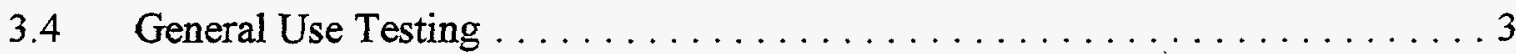

3.4.1 Acceleration (wide-open throttle) testing

3.4.2 Periodic battery testing

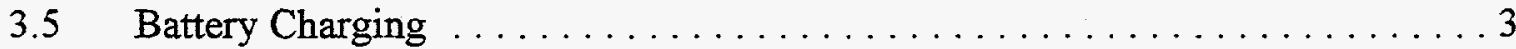

- $\quad$ recharge algorithm optimization

- $\quad$ self-discharge compensation

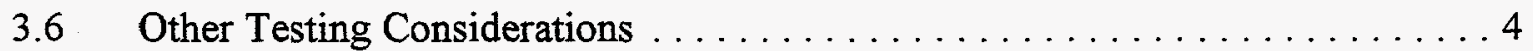

- battery discharge behavior

- $\quad$ environmental conditions

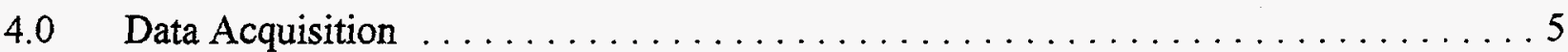

$4.1 \quad$ Measurements . . . . . . . . . . . . . . . . . . . . . 5

4.2 Data Recording/Equipment Capabilities .................. 5

$5.0 \quad$ Data Retention . . . . . . . . . . . . . . . . . . . . . . . 6

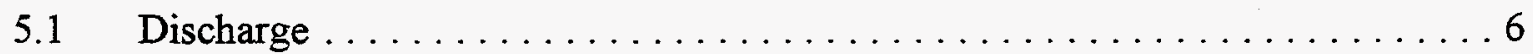

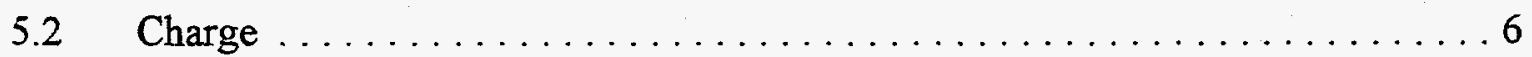

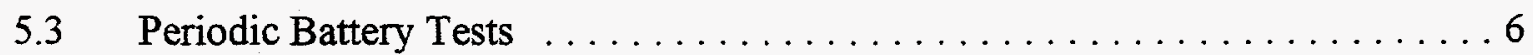

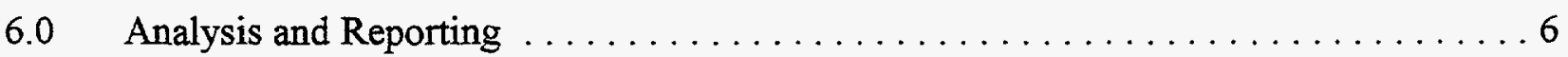

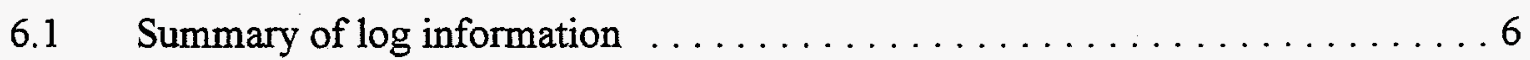

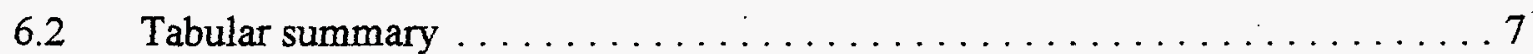

6.3 Standard analysis of periodic performance tests $\ldots \ldots \ldots \ldots \ldots \ldots \ldots$

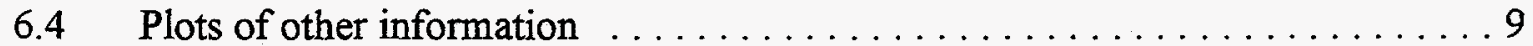

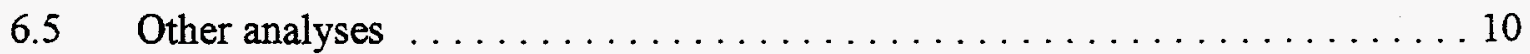




\section{FIGURES}

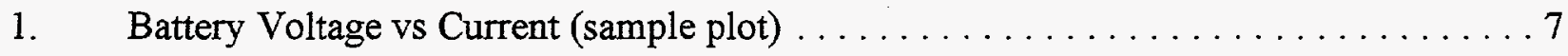

2. Battery Voltage \& Resistance vs $\%$ DOD (sample plot) $\ldots \ldots \ldots \ldots \ldots \ldots \ldots$

3. Battery Module Voltage \& Resistance vs $\%$ DOD (sample plot) . . . . . . . . . . 8

4. Estimated Peak Power Capability vs $\%$ DOD (sample plot) . . . . . . . . . . . 9

5. Battery Voltage \& Resistance over Life (sample plot) . . . . . . . . . . . . . 9

6. Estimated Peak Power Capability over Life (sample plot) . . . . . . . . . . . 10

7. Capacity and Peak Power over Battery Life (sample plot) $\ldots \ldots \ldots \ldots \ldots \ldots \ldots$

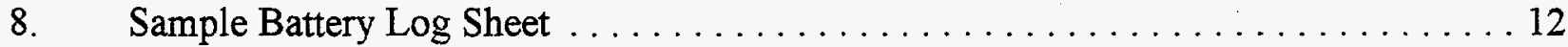




\section{IN-VEHICLE BATTERY TESTING TEST PROCEDURE}

\subsection{Goal}

Conduct a program of use testing of battery packs in electric vehicles to extract batteryrelated information to be used for feedback into the USABC battery development program.

\subsection{Approach}

This testing will be conducted in concert with planned "durability" or use testing of a group of electric vehicles, to be conducted by auto company EV platform groups at one or more proving grounds. The basic testing program will be determined by the intended vehicle use, with battery-related data to be gathered as an adjunct activity. This means that testing of the vehicle(s) will generally be the dominant activity. However, some perturbation of the vehicle operation is assumed to be possible where necessary to acquire suitable battery data. Data is assumed to be collectible by automated on-board data logging equipment as well as from driver/test logs.

\subsection{Testing and Test Operations}

\subsection{Battery Acceptance and Installation - A battery pack and any supporting} components or subsystems shall be inspected for damage, weighed and measured (all dimensions) prior to installation in a vehicle. Any required sensors and associated cabling shall also be installed and checked before battery installation. This may be done by the battery supplier using a USABC checklist. The supplier's capability to perform this work shall be verified by the USABC Program Manager.

Battery core performance tests shall be performed to determine power, energy, $A \cdot h$ capacity, etc. of the actual batteries to be used, using existing USABC test procedures. These tests can be performed in a laboratory by the supplier prior to installation provided the supplier has been determined to have the capability for this testing; otherwise they will have to be performed by an outside test facility. Documentation shall be provided on the results of this testing, showing summary results and data. 
3.2 Post-Installation Checkout - After installation, the mechanical integrity of all connections shall be verified, and on-board data gathering equipment shall be made operational before testing begins. Preliminary checks shall be made to determine adequate electrical isolation and ground fault protection.

Any battery control subsystems (e.g. thermal management or on-board charging capabilities) shall be determined to be functioning. A short period of vehicle operation (approximately 50 miles) is necessary to disclose any obvious problems in battery operation before formal testing begins. A test orientation meeting shall be held with supplier, proving ground and USABC personnel before testing begins.

3.3 Preliminary Field Testing - Prior to the beginning of controlled durability/general use testing at a proving ground or other field test location, a number of controlled tests shall be performed on the battery/vehicle to establish the (operational and safety) condition of the battery, its baseline performance, and its suitability for more systematic testing. These should generally be conducted at the proving ground with the active involvement of the battery supplier and should include the following:

Vehicle compatibility checks shall be done to establish electrical isolation, ground fault protection, proper functioning of on-board charger and thermal management system, battery gassing rate if applicable. Off-board charging facilities shall be checked and calibrated for proper operation. Procedures for the operation of all vehicle and battery systems shall be verified.

Preliminary vehicle/battery performance trials under controlled conditions (e.g. dynamometer) shall be done to determine baseline battery system performance. One suggested set of such tests is as follows: 


\begin{tabular}{|c|c|c|}
\hline TYPEOP TEST & NO REPS' & EOCATION \\
\hline Constant speed/constant load ${ }^{2}$ & $\begin{array}{l}2 \text { at each of } 3 \\
\text { loads }\end{array}$ & Dynamometer \\
\hline Continuous FUDS profiles & 3 & Dynamometer \\
\hline Continuous FUDS/HWFET profiles (SAE J1634) & 3 & Dynamometer \\
\hline Max acceleration (wide-open throttle) & $\begin{array}{l}2 \text { (at } 10 \text { depths } \\
\text { of discharge) }\end{array}$ & $\begin{array}{c}\text { Track \& } \\
\text { Dynamometer }\end{array}$ \\
\hline $\begin{array}{l}\text { Self-discharge (loss of capacity with stand time) - FUDS } \\
\text { with varying wait times after recharge }(1,2,4,8,16,48 \\
\text { hours) }\end{array}$ & $\begin{array}{l}2 \text { or } 1 \text { depending } \\
\text { on wait }\end{array}$ & Dynamometer \\
\hline \multicolumn{3}{|c|}{$\begin{array}{l}\text { Notes: } \\
\text { 1. i.e. complete battery discharge cycles under the listed conditions } \\
\text { 2. The intention is to produce approximately constant power discharges from the battery } \\
\text { 3. Corresponding approximately to } 1,2 \text { and } 3 \text { hour discharge rates for the battery }\end{array}$} \\
\hline
\end{tabular}

Particular attention shall be given to battery charging during this preliminary operation period. The charge algorithm shall be verified from actual data to the extent possible, and the charger calibration shall be checked.

After the preliminary checkouts described above have been completed at the proving ground, break-in testing shall be conducted for at least 2 weeks (or as required) to practice the driving/charging/data logging process. Samples of data from this activity shall be reviewed by the USABC Program Manager prior to the start of a formal use testing phase.

3.4 General Use Testing - A repetitive daily pattern of driving activity shall be used, i.e. a given vehicle shall be driven the same way every day for at least part of the time. Different driving patterns and environmental conditions are likely to be used for a given vehicle (and certainly for different vehicles) over time; but some repetitive driving behavior will allow for much simpler data reduction and analysis compared to random driving.

The exact nature of the testing to be done necessarily depends on both the data to be acquired and the measurement capability available. At least the following special types shall be considered: 


\subsubsection{Acceleration (Wide-open Throttle) Testing - The initial wide-open throttle}

(WOT) performance cycles shall be repeated at approximately regular intervals (e.g. daily, monthly or at fixed mileage intervals) on the test track. Each such operation shall include a maximum effort acceleration (from 0 to 60 mph or maximum speed) several times during a battery discharge to provide data on battery behavior under maximum load. This will provide periodic estimates of module resistance rise over battery life.

3.4.2 Periodic Battery Testing - At regular intervals during the use testing (e.g. monthly or at a fixed mileage interval, e.g. every 2000 or 5000 miles), the battery shall be subjected to a discharge capacity test under controlled conditions. This should be done by performing the SAE J1634 Range Test on a dynamometer (with additional tests if desired) and reporting the results as described in Analysis and Reporting Section 6.3.

For this testing, the dynamometer road load should be set to predetermined values which are calculated to produce battery peak powers on the FUDS corresponding to the USABC goal applied to the battery pack under test, e.g. $120 \mathrm{~W} / \mathrm{kg}$ of battery system weight. These values must be determined within the testing organization based on the characteristics of the test bed vehicle, but they need not be disclosed. Actual vehicle coastdown data is not required for this approach. However, it might be useful to perform a vehicle coastdown test initially and at intervals of several months to verify that the load presented to the battery is not changing over time. (This vehicle coastdown data need not be shared outside the test site.)

\subsection{Battery Charging}

The use (or not) of opportunity charging to permit more miles/hours of use to be accumulated in a day shall be considered. (Note that the use of opportunity charging may complicate data recording if more than one charge location is used.) If some of the batteries are configured as two parallel strings, stringent control of recharging procedures will be required in the field to assure the string capacities remain balanced during testing. 
Recharge Algorithm Optimization - The amount of overcharge required to keep the modules in a balanced state-of-charge shall be determined for at least one battery system of a given type. This can be done by measuring the responses of the individual modules in a pack during the periodic dynamometer discharge tests. The manufacturer-specified charging approach shall be used for TBD total miles of operation. Manufacturer-specified variations in recharge control can then be used for similar periods of operation, and the rate of change in module SOC uniformity can be tracked and correlated with the control variations.

Self-discharge compensation - testing should be done (again for at least one battery system of a given type) to determine how to keep the battery fully charged while connected to the charging station, i.e. compensating for short-term self-discharge after recharge. Two candidate methods for doing this are:

(1) Periodic "top-up" of the battery charge at low current every TBD minutes

(2) Continuous application of a TBD safe "float voltage", varying with temperature

These methods can be evaluated by evaluating the periodic dyno discharge data using a fixed wait period between the end of normal recharge and start of the discharge.

Fast Charging - In some cases fast charge capabilities may be provided for a given battery. This will require special charge-related procedures which are not yet available.

\subsection{Other Testing Considerations}

Battery Discharge Behavior - An up-front determination shall be made as to whether the test program will/should completely discharge the battery during each day's operation, or whether some testing will be done using partial discharge/recharge cycles for an extended period of time. (Periodic reference tests on the dynamometer per 3.4.2 should always be complete discharge tests.)

Environmental Conditions - The test program will include deliberate variations in environmental conditions (using either proving grounds in climatically different locations, such as Arizona or Canada, and/or environmental chambers with dynamometers.) Particular attention shall be given to charge procedures and 
algorithms and thermal management during both charging and driving under severe environmental conditions.

\subsection{Data Acquisition}

4.1 Measurements - The following parameters shall be measured during the various testing phases. (Note that the vehicle-specific data is not expected to be reported to the USABC.)

- $\quad$ Preliminary Testing - as specified for the various procedures used

- $\quad$ Periodic Battery Testing - See table following

- Use/Durability Testing - the information in the following table shall be recorded if available.

Measurements \& Other Data to be Recorded

\begin{tabular}{|l|l|}
\hline Driving/ Battery & $\begin{array}{l}\text { As a function of Time: } \\
\text { Battery Pack Voltage, Current } \\
\text { Module(s) Voltage } \\
\text { String Current (if more than one string) } \\
\text { Battery/Ambient Temperature } \\
\text { Speed (diagnostic only, not reported) } \\
\text { Vehicle (key) On/Off Status? }\end{array}$ \\
\hline Battery Recharge & $\begin{array}{l}\text { Battery Voltage, Current and Temperature vs Time } \\
\text { Other (Log Sheets/Books) }\end{array}$ \\
$\begin{array}{l}\text { Daily logs of driver, mileage (starting and } \\
\text { ending odometer) and date/time; } \\
\text { charger AC A-h and/or W·h and \# cycles, } \\
\text { including partial charges; } \\
\text { delays, changes or deviations in test } \\
\text { activities; } \\
\text { battery-related maintenance (especially } \\
\text { failures or replacements); } \\
\text { unusual environmental info (e.g. ambient } \\
\text { temperature, humidity, rain/snow), etc. }\end{array}$ \\
\hline
\end{tabular}

An example log sheet draft is attached. (This example incorporates only a minimum subset of the data listed above.) 


\subsection{Data Recording Equipment/Capabilities}

Battery Overall V and I:

Accuracy

Resolution

Sampling Rate
$1 \%$ or better

$0.2 \mathrm{~V}, 0.15 \mathrm{~A}$

1 second (discharge)

3 minute (charge)

Logging Rate

Time Skew between V and I
1 second (discharge) ${ }^{1}$

1-5 minute intervals (charge)

0.1 second or less (necessary for power and resistance determination)

Note ${ }^{1}$ : Required over full discharge only for dyno tests

Module V, String I:

Resolution

$0.1 \mathrm{~V}$

Other requirements same as Battery $\mathrm{V}$ and $\mathrm{I}$, including time skew between module $\mathrm{V}$ and corresponding $\mathrm{I}$

Temperatures (Battery and Ambient)

Accuracy

Logging Rate $3^{\circ} \mathrm{C}$

5 minute intervals ( 1 minute intervals for module temperatures for special tests)

\subsection{Data Retention}

5.1 Discharge - for each day's operation, data to be retained shall include battery V/I vs time data for selected data segments (e.g. accelerations) along with all summary measured or calculated data $(\mathrm{A} \cdot \mathrm{h}, \mathrm{W} \cdot \mathrm{h}, \min / \max$ temperatures etc.). Module $\mathrm{V} / \mathrm{I}$ and temperature vs time data shall also be retained for the selected data segments at least until reviewed. If all detailed (second by second) data is not to be retained, data shall also be aggregated to build distributions of current, power, temperature etc. over each day and subsequently for the entire test program. 
5.2 Charge - Primary charge data to be retained would include daily/cycle summary information such as $\mathrm{A} \cdot \mathrm{h}$ and $\mathrm{W} \cdot \mathrm{h}$ returned and $\mathrm{min} / \mathrm{max}$ temperatures. Daily/cycle $\mathrm{AC} \mathrm{A} \cdot \mathrm{h}$ input to the charger shall also be retained. At some interval (weekly or monthly) the actual V/I vs time data for the battery and modules shall also be retained.

5.3 Periodic Battery Tests - data from dynamometer reference tests shall be retained indefinitely unless written notice to the contrary is provided by the USABC Program Manager.

\subsection{Analysis and Reporting}

All the retained data shall be added to a data base to make it available for review on demand. Pre-determined reporting shall include at least the following information.

6.1 Summary of log information at monthly intervals, including a summary of the daily information identified in the Measurements table under Other (e.g days of operation, $\mathrm{A} \cdot \mathrm{h}$ and $\mathrm{W} \cdot \mathrm{h}$, charge cycles, issues/status/solutions/action items, average/minimum/maximum temperatures encountered.)

6.2 Tabular summary of performance information derived from periodic capacity tests, including capacity, number of discharge/charge cycles between tests.

6.3 Standard analysis of periodic performance tests to derive battery open circuit voltage and resistance. An outline of this process is as follows: (Detailed procedure will be needed.)

6.3.1 Plot the battery paired V-I data (and corresponding data for each module if available) in appropriate size blocks (e.g. 343 seconds, or 1/4 of a FUDS profile, if the periodic test includes FUDS testing; or each segment of stopand-go data for the alternate track test.) Use linear regression to fit the block of data. (Assure $r^{2} \geq 0.90$ if possible.) See Figure 1 for an example of such data for a complete battery and the resulting regression results. 


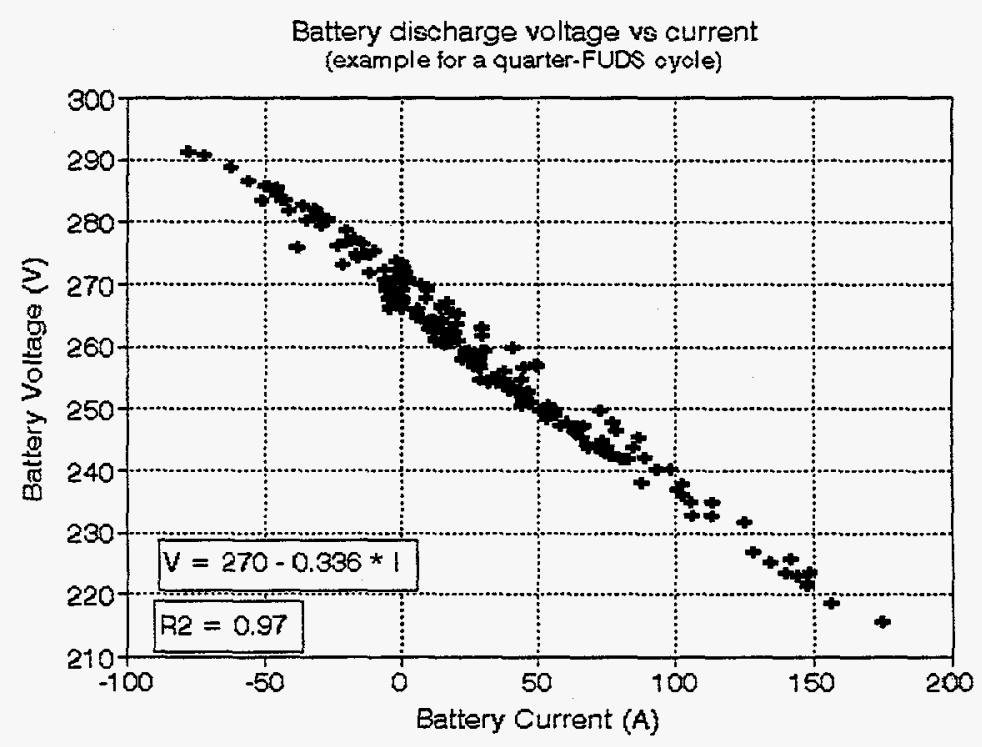

Figure 1. Battery Voltage vs Current

6.3.2 Obtain the values of open-circuit voltage (OCV) and resistance $(\mathrm{R})$ from the linear regressions for each module at each available DOD (arbitrarily assigned to the endpoint of the data block.) Plot battery voltage and resistance as a function of $\%$ DOD using these results. (See Figure 2 for an example of such data.)

6.3.3 If module data is available, plot the average module OCV and $\mathrm{R}$ (same as battery $\mathrm{OCV}$ and $\mathrm{R}$ divided by number of modules) and the minimum and maximum values for the set of modules, at each DOD value. (Figure 3 illustrates such data.) The standard deviations of $\mathrm{OCV}$ and $\mathrm{R}$ at each DOD can also be calculated and plotted (not shown here.)

6.3.4 Use the battery voltage and resistance for the pack to estimate the total pulse power capability for the battery. This is done by using the open-circuit voltage and resistance at each DOD calculated in 6.3.2 and the following formula derived for the USABC Peak Power Test:

Peak Power Capability $=(2 / 9)^{*}\left(\mathrm{~V}_{\text {irfree }}\right)^{2} /$ Resistance

Figure 4 is an example of the resulting data plot. 


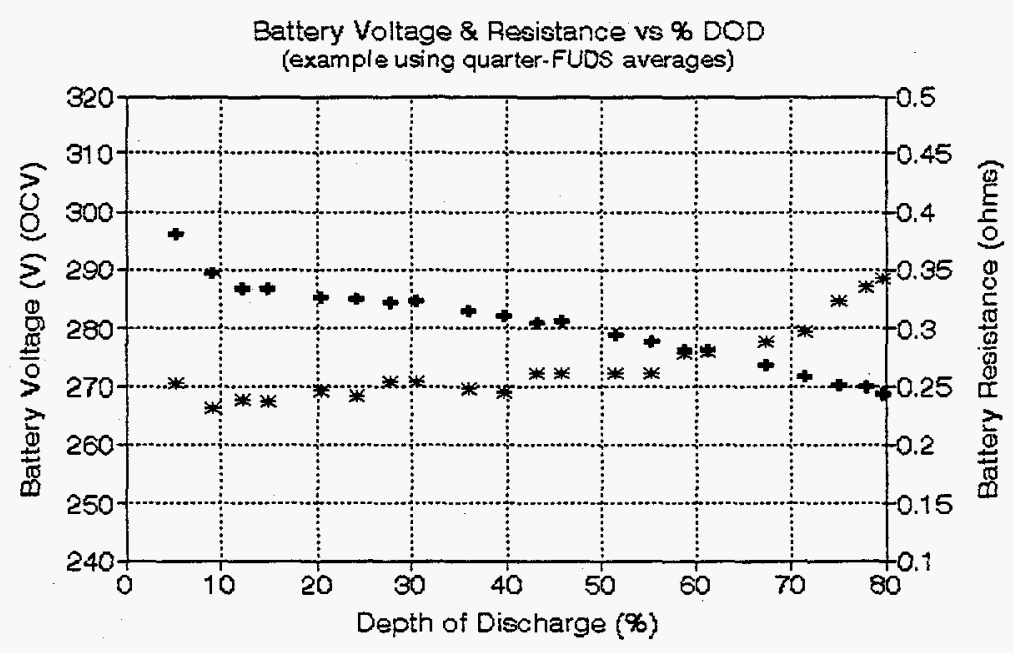

* Virfree * Resistance

Figure 2. Battery Voltage \& Resistance vs \% DOD

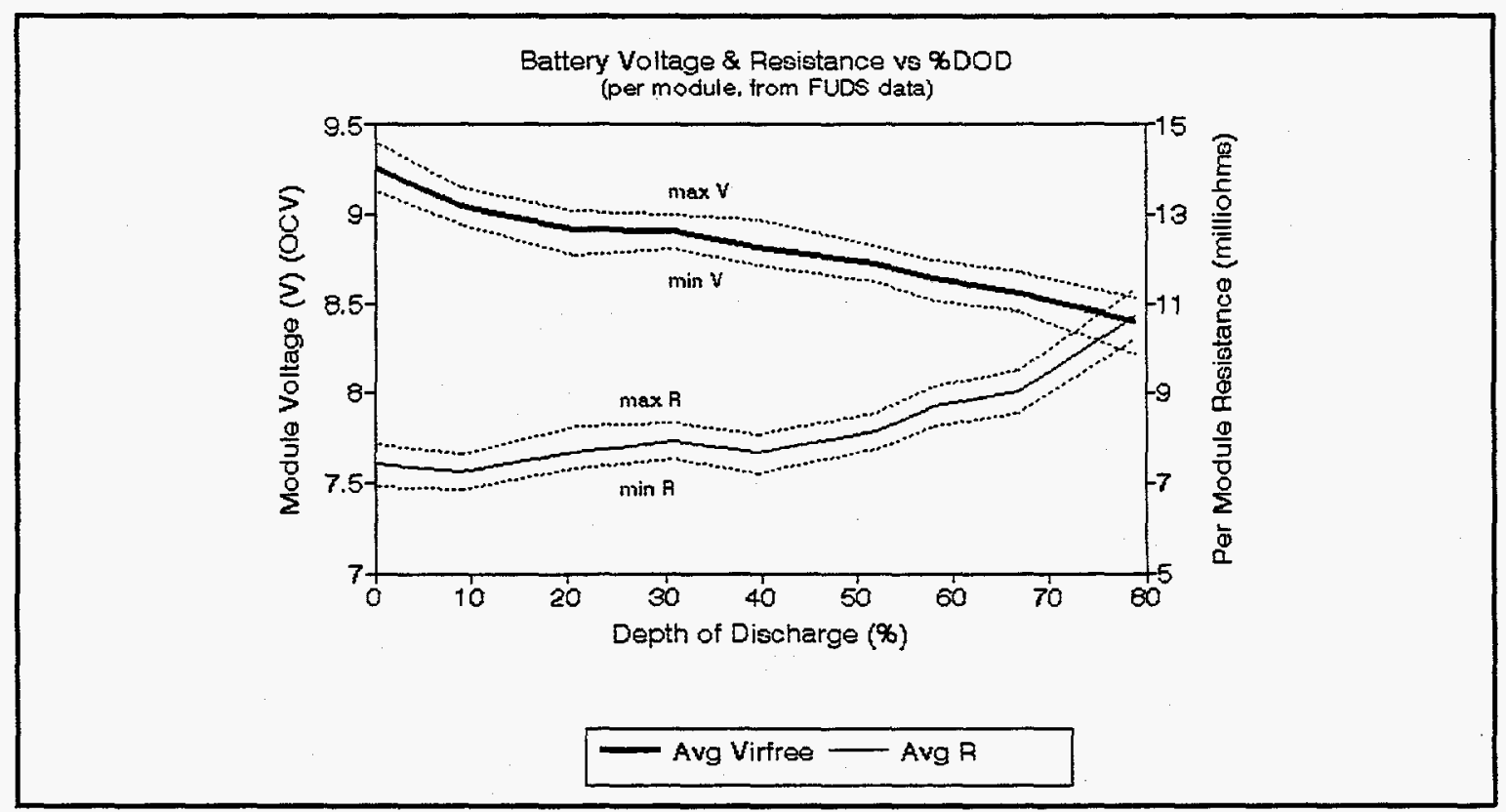

Figure 3. Battery Module Voltage \& Resistance vs $\%$ DOD 


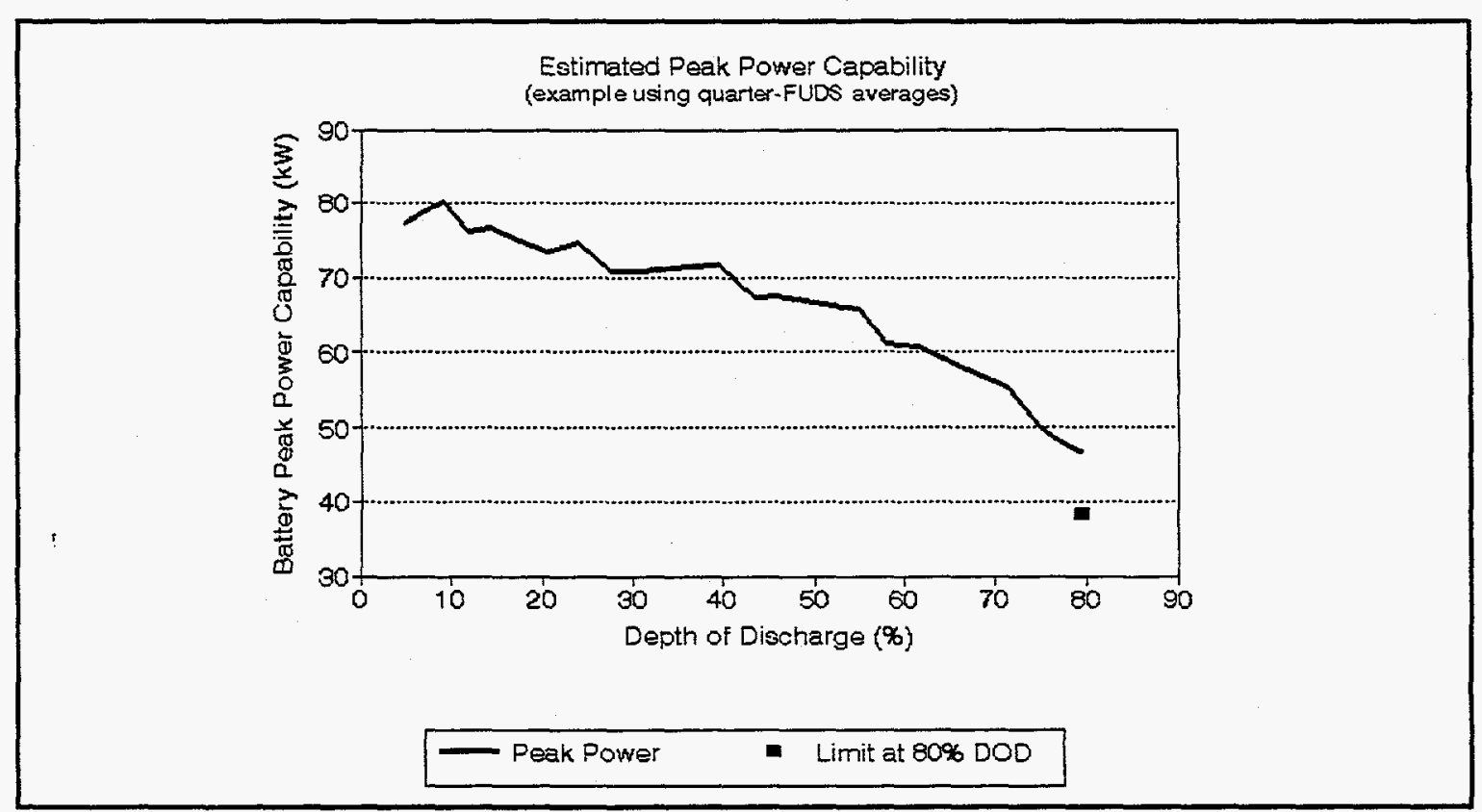

Figure 4. Estimated Peak Power Capability vs \% DOD.

6.4 Plots of other information obtained from daily operation shall be reported at some predetermined interval (e.g. weekly or monthly):

- Battery and/or module open circuit voltage and resistance at a consistent DOD (preferably $80 \%$ ) as a function of cumulative ampere-hours discharged or 'equivalent cycles'. ('Equivalent cycles' is the cumulative ampere-hours divided by $80 \%$ of the rated capacity of the battery.) Figure 5 is an example of such data.

- Battery peak power capability can also be plotted as a function of cumulative ampere-hours or equivalent cycles. (See Figure 6 for example.)

- Module voltage spread under maximum load (WOT test data), as a function of ampere-hours or cycles

- Battery capacity in ampere-hours and kilowatt-hours (from periodic capacity tests, unless the battery is completely discharged daily), as a function of cumulative ampere-hours or battery cycles. This can be plotted separately, or combined with the peak power history as shown in Figure 7. 


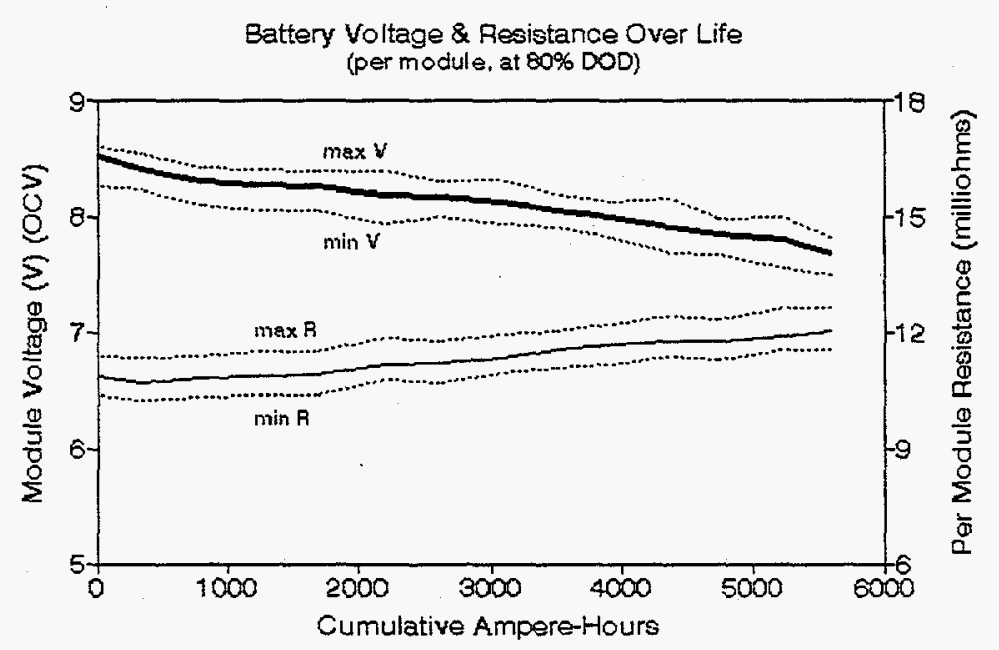

Avg Virfree $\longrightarrow$ Avg $R$

Figure 5. Battery Voltage \& Resistance over Life

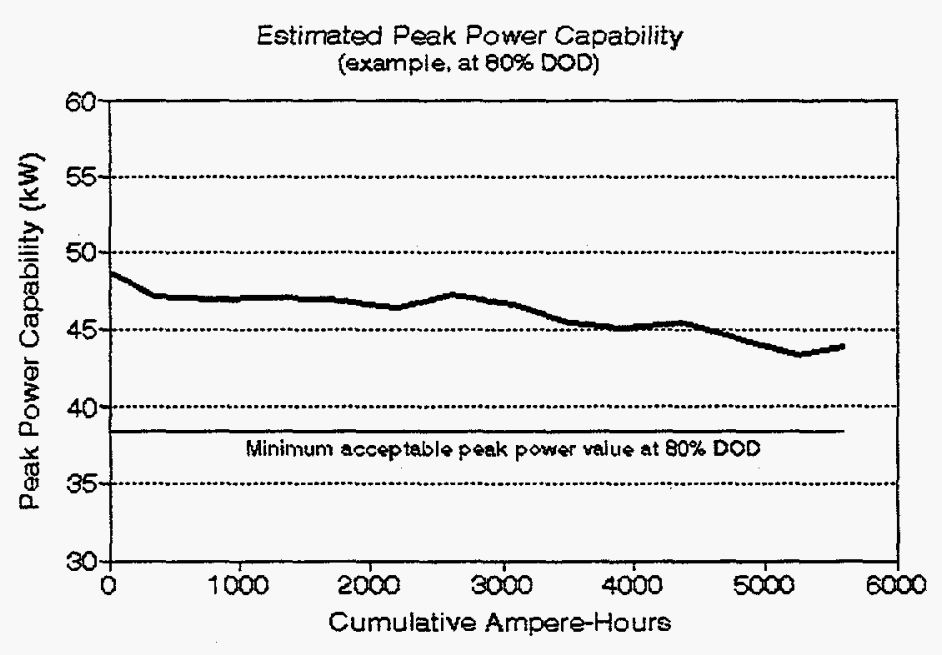

Peak Pwr (battery)

Figure 6. Estimated Peak Power Capability over Life 


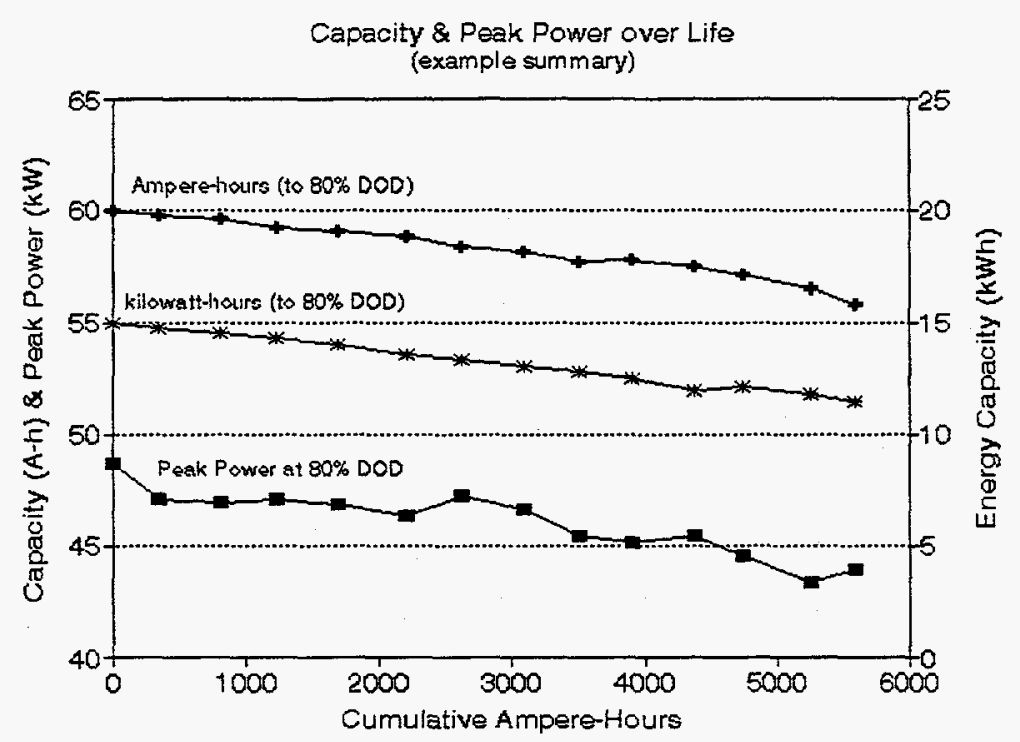

Figure 7. Capacity and Peak Power over Battery Life

- Average daily temperature (over the discharge cycle), as a function of cycles

- Recharge, in $\mathrm{A} \cdot \mathrm{h}$ and percent of previous discharge, as a function of cycles

6.5 Other Analyses will be performed as appropriate based on selected detailed data to be made available for the purpose. For example, it is anticipated that dynamic state-ofcharge (SOC) estimation algorithms will be developed using the initial performance data for capacity under various constant loads as well as the FUDS measured capacity. These may be supplemented with FUDS profiles with varying maximum power. (This can be accomplished on a dynamometer by programming the load for appropriately.) The effects of stand time can also be included using the self-discharge data described under Preliminary Testing. 
Sample Battery Log Sheet

BATTERY CHARGING LOG

BATTERIES VEH NO.

\begin{tabular}{|c|c|c|c|c|c|}
\hline \multirow[t]{2}{*}{ Date } & \multirow{2}{*}{$\begin{array}{l}\text { Charge Time } \\
\text { Guloff }\end{array}$} & \multicolumn{2}{|c|}{ Charge } & \multicolumn{2}{|c|}{ Discharge } \\
\hline & & Ah In & I Wh In & Al Out & kWh Out \\
\hline & & & & & \\
\hline & & & & & \\
\hline & & & & & \\
\hline & & & & & \\
\hline & & & & & \\
\hline & & & & & \\
\hline & & & & & \\
\hline & & & & & \\
\hline & & & & & \\
\hline & & & & & \\
\hline & & & & & \\
\hline & & & & & \\
\hline & & & & & \\
\hline & & & & & \\
\hline & & & & & \\
\hline & & & & & \\
\hline & & & & & \\
\hline & & & & & \\
\hline & & & & & \\
\hline & & & & & \\
\hline & & & & & \\
\hline & & & & & \\
\hline & & & & & \\
\hline
\end{tabular}

